\title{
PERILAKU BULLYING DENGAN BURNOUT KARYAWAN
}

\author{
Catherine Chuang ${ }^{1}$ \\ Fakultas Psikologi, Program Studi Psikologi, Universitas Prima Indonesia \\ catherine.chuang97@gmail.com
}

\begin{abstract}
This study is purposed to determine the relationship between bullying and burnout among the employees. The samples used in this study is all employees of PT. Bank Central Asia.The scale for measuring bullying and burnout is given to 73 employees that has been chosen with total sampling technique.The analysis of the data in this study is using the Pearson Product Moment Correlation. The result of this study showed that the coefficient $r=0,434$ with $p=0,000$, which means that there is a positive relationship between bullying and burnout. This means that the higher the tendency of bullying experienced by employess, the higher burnout experienced will be happened to the employees, and vice versa.

Keyword: Up to six keywords should also be included.
\end{abstract}

\begin{abstract}
Abstrak
Tujuan penelitian ini adalah untuk mengetahui hubungan bullying di tempat kerja terhadap kejadian burrnout pada karyawan. Subjek dalam penelitian ini adalah semua karyawan yang bekerja di PT. Bank Central Asia cabang Asia. Kuesioner yang memuat skala untuk mengukur bullying dan burnout, yang sebelumnya telah disesuaikan menurut Maslach, dkk., (1997) dan Enairsen, dkk., (2009) diberikan kepada 73 orang karyawan yang dipilih melalui metode total sampling. Analisis data pada penelitian ini menggunakan korelasi Product Moment Pearson.. Hasil Penelitian ini menunjukkan nilai koefisien $\mathrm{r}=0,434 ; \mathrm{p}<0,05$ yaitu terdapat hubungan positif antara bullying dan burnout, dan hipotesis diterima. Artinya, semakin rendah bullying yang di alami oleh karyawan maka semakin rendah burnout karyawan pada perusahaan. Atau sebaliknya semakin tinggi bullying yang di alami karyawan maka semakin tinggi burnout karyawan pada perusahaannya.

Kata kunci: burnout, bullying.
\end{abstract}




\section{PENDAHULUAN}

Bekerja merupakan salah satu aspek yang penting dalam kehidupan manusia saat ini untuk memenuhi kebutuhan dan kebanyakan karyawan menghabiskan waktu rata-rata delapan jam sehari di tempat kerjanya (Harter, dkk., 2002). Kehidupan kerja juga menjadi hal yang penting bagi setiap instansi karena di era kompetisi global ini, setiap instansi dihadapkan pada lingkungan kerja yang kompleks dan dinamis, yang mana kondisi ini memberi cukup tekanan pada pekerja untuk lebih fleksibel, bervisi, dan inovatif dalam bekerja (Ballou \& Goldwin, 2007). Kondisi kehidupan kerja yang membuat karyawan tidak nyaman dan tertekan dapat membuatnya mengalami burnout.

Pernyataan tersebut didukung oleh hasil temuan Miller (2000) yang mengatakan bahwa burnout digambarkan sebagai suatu ekspresi ekstrim stres kerja tahap akhir dari proses dan frustasi pada individu pekerja atau sebagai titik kelelahan. Menurut Kreitner dan Kinicki (1992) burnout adalah akibat dari stres yang berkepanjangan dan terjadi ketika seseorang mulai mempertanyakan nilai-nilai pribadinya.Sumber atau penyebab terjadinya burnout yaitu kelebihan beban kerja, kurangnya kontrol, sistem imbalan yang tidak memadai, hilangnya keadilan, dan konflik nilai (Maslach \& Leiter, 1997).

Berdasarkan penelitian Mohammadbagher Goji tahun 2011 tentang status kejenuhan kerja dengan kerja pada pegawai bank menunjukkan bahwa 30,75\% pegawai rata-rata mengalami kejenuhan kerja, menekankan bahwa kejenuhan kerja ini dirasakan oleh pegawai yang sudah bekerja antara 3 - 5 tahun, dan lebih dominan terjadi pada jenis kelamin laki-laki. Sedangkan hasil penelitian menunjukkan adanya kejenuhan (burnout) tinggi pada pegawai yang berakibat pada kinerja pegawai, ini berarti kinerja pegawai menurun karena kejenuhan kerja meningkat (Maharani \& Triyoga, 2012).

Hasil temuan Marks (dalam Rayner, dkk., 2002), bullying adalah perilaku yang tidak diinginkan apakah itu secara fisik atau secara lisan yang menyinggung, memalukan, dan dipandang sebagai hal yang tidak dapat diterima oleh penerima. Rudi (2010) menambahkan bahwa workplace bullying merupakan perilaku dan praktik negatif secara berulang yang ditujukan kepada satu atau beberapa pekerja, sehingga berakibat pada ketidakberdayaan dan penderitaan psikologis yang mempengaruhi perilaku seorang pekerja dan kinerjanya di sebuah instansi ataupun organisasi.

Beberapa tahun belakangan ini semakin banyak bermunculan penelitian mengenai perilaku bullying terhadap kejadian burnout, terutama pada karyawan. Tekanan kebutuhan pasar dan ketatnya persaingan dunia usaha pada akhirnya mendorong perusahaan untuk menetapkan 
berbagai kebijakan terkait dengan karyawannya, bahkan tidak jarang perusahaan menekan karyawan untuk meningkatkan produktivitas sampai titik yang diharapkan. Kebijakan tersebut seringkali menempatkan karyawan dalam tekanan dan ketidakpastian. Hal inilah yang seringkali memicu stres kerja pada karyawan yang apabila dialami individu dalam jangka waktu lama dengan intensitas cukup tinggi akan mengakibatkan individu yang bersangkutan menderita kelelahan fisik, emosional, maupun mental, keadaan seperti ini disebut sebagai burnout (Andriansyah \& Sahrah, 2014).

Sementara itu, hasil survei dari careerbuilder.com pada tahun 2007 melaporkan bahwa 77\% dari pekerja Amerika merasakan kejenuhan (burnout) di tempat kerjanya (Lorenz, 2006). Selain itu, ditemukan pula bahwa karyawan yang menerima pembulian di tempat kerja mencapai $27 \%$. Survei tersebut juga menunjukkan sebanyak $21 \%$ karyawan hanya menyaksikan pembulian di tempat kerja terjadi dan kemudian diri mereka mengalami kejenuhan dalam bekerja. Sementara $72 \%$ lainnya menyadari adanya pembulian di perusahaan tempat ia bekerja. Pada akhirnya, para karyawan tersebut mengalami ketidakstabilan secara emosional, bahkan mengalami kejenuhan dalam bekerja dan akhirnya 29\% dari karyawan tersebut memutuskan untuk keluar dari pekerjaan mereka (www.workplacebullying.org).

Penelitian yang dilakukan oleh Einarsen dan Raknes (1997) menunjukkan bahwa bullying di tempat kerja dapat meningkatkan keluhan-keluhan psikologis dan burnout pada karyawan. Penelitian tersebut melibatkan 464 orang karyawan pria yang bekerja pada industri mesin dan sebanyak $88,5 \%$ dari responden menyatakan bahwa setidaknya mereka mengalami satu kali tindakan bullying dalam enam bulan terakhir mereka bekerja baik.

Berdasarkan uraian di atas, maka peneliti tertarik untuk meneliti mengenai bullying di tempat kerja dan burnout pada karyawan. Adapun rumusan masalah yang penulis ajukan adalah "Apakah ada hubungan positif dan signifikan antara perilaku bullying dengan burnout pada karyawan?" Hipotesis yang penulis ajukan adalah Ada hubungan positif dan signifikan antara cyberbullying dengan burnout karyawan.

\section{METODE}

Populasi pada penelitian ini adalah seluruh karyawan yang bekerja di PT Bank Central Asia yang terletak di Jln. Asia simpang Bakaran Batu No. $1 \mathrm{C}$ dengan jumlah 73 orang. Menurut Arikunto (2006), melihat jumlah populasi yang relatif kecil, yakni kurang dari 100 orang, maka akan lebih baik apabila seluruh anggota populasi dijadikan subjek penelitian. Atas dasar pertimbangan tersebut maka teknik pengambilan sampel yang penulis gunakan dalam penelitian ini adalah total sampling. Dengan 
kata lain, seluruh karyawan yang bekerja di PT. Bank Central Asia Tbk cabang Asia yang seluruhnya berjumlah 73 orang diambil sebagai sampel penelitian. Metode pengumpulan data yang digunakan dalam penelitian ini adalah metode pengumpulan skala sebagai instrument penelitian. Sebelum menyatakan berpartisipasi, partisipan diminta untuk menyetujui informed consent secara lisan.

Alat ukur yang digunakan dalam penelitian ini terdiri dari kuisioner yang berisikan identitas dan data demografis (usia, jenis, kelamin, jabatan) serta dua skala likert yang masing - masing mengukur tentang burnout dan bullying yang memuat skala favorable dan unfavorable. Tahapan penyusunan kuesioner untuk burnout dibuat berdasarkan dimensi - dimensi yang dikemukan oleh Maslach, dkk., (1997) yang terdiri atas exhaustion, cynicism, dan inffectiveness yang terdiri dari 30 aitem dan diukur dengan penjumlahan skor pada skala tersebut. Penyusunan kuesioner untuk skala bullying pada penelitian ini didasarkan pada dimensi yang dikemukakan oleh Enairsen, dkk., (2009) meliputi workrelated bullying, person-related bullying, dan physical intimidation bullying yang juga terdiri dari 30 aitem.

Analisis data yang digunakan antara lain menggunakan korelasi Pearson Product Moment. Metode ini digunakan untuk mengetahui hubungan antara variabel burnout dan bullying. Analis korelasi ini menggunakan bantuan software SPSS (Statistical Package for Social Sciences) versi 21.0.

\section{HASIL DAN PEMBAHASAN}

Penelitian ini menggunakan subjek sebanyak 73 orang. Data yang akan dianalisis diperoleh dengan cara menyebar skala burnout dan bullying. Berikut merupakan tabel kategorisasi data burnout dan bullying :

Tabel 1

Kategorisasi Data Burnout dan Bullying

\begin{tabular}{lllllll}
\hline \multirow{2}{*}{ Kategorisasi } & \multirow{6}{c}{ Variabel } \\
\cline { 2 - 7 } & Bullying & Jumlah (n) & $\%$ & Burnout & Jumlah (n) & $\%$ \\
\hline Rendah & $\mathrm{x}<60$ & 16 & 21,92 & $\mathrm{x}<60$ & 1 & 1,4 \\
\hline Sedang & $60 \leq \mathrm{X}<90$ & 57 & 78,08 & $60 \leq \mathrm{X}<90$ & 72 & 98,6 \\
\hline Tinggi & $\mathrm{x} \geq 90$ & 0 & 0 & $\mathrm{x} \geq 90$ & 0 & 0 \\
\hline Total & & 73 & 100 & & 73 & 100 \\
\hline
\end{tabular}

Pada tabel 1 diatas terlihat bahwa tidak ada subjek dengan burnout tinggi, sebanyak 1 orang atau 1,4 persen yang memiliki burnout rendah dan subjek yang memiliki burnout sedang ada sebanyak 72 orang atau 98,6 persen. Pada tabel diatas juga dapat dilihat bahwa terdapat subjek dengan bullying rendah sebanyak 16 orang atau 21,92 persen, sedangkan subjek yang 
mendapatkan bullying sedang adalah sebanyak 57 orang atau 78,08 persen, dan tidak dijumpai adanya subjek yang mendapatkan bullying tinggi.

Tabel 2

Perbandingan Data Empirik dan Hipotetik Bullying dan Burnout

\begin{tabular}{lllllllll}
\hline \multirow{2}{*}{ Variabel } & \multicolumn{2}{l}{ Skor Empirik } & \multicolumn{7}{l}{ Skor Hipotetik } \\
\cline { 2 - 9 } & Min & Max & Mean & SD & Min & Max & Mean & SD \\
\hline Bullying & 45 & 80 & 65,26 & 7,128 & 30 & 120 & 75 & 15 \\
\hline Burnout & 54 & 80 & 72,00 & 5,233 & 30 & 120 & 75 & 15 \\
\hline
\end{tabular}

Hasil analisis padatabel 2 menunjukkan bahwa untuk skala burnout, diperoleh mean empirik $<$ mean hipotetik yaitu $72<75$ maka dapat disimpulkan bahwa kejadian burnout pada penelitian lebih rendah daripada populasi pada umumnya, sedangkan hasil analisis untuk skala bullying, diperoleh mean empirik <mean hipotetik yaitu 65,26< 75 maka dapat disimpulkan bahwa kejadian burnout pada penelitian jugalebih rendah daripada populasi pada umumnya.

Tabel 3

Hasil Uji Normalitas

\begin{tabular}{llllll}
\hline Variabel & SD & K-SZ & Sig (1-tail) & $\mathrm{p}$ & Keterangan \\
\hline Burnout & 5,233 & 0,878 & 0,212 & $\mathrm{p}>0,05$ & Sebaran normal \\
\hline Bullying & 7,128 & 0,987 & 0,1425 & $\mathrm{p}>0,05$ & Sebaran normal \\
\hline
\end{tabular}

Uji normalitas dilakukan agar dapat mengetahui apakah setiap variabel penelitian telah menyebar secara normal atau tidak. Uji normalitas sebaran menggunakan uji Kolmogorov Smirnov Test. Data dikatakan berdistribusi normal jika $\mathrm{p}>0,05$. Uji normalitas yang dilakukan terhadap variabel burnout koefisien $\mathrm{KS}-\mathrm{Z}=0,878$ dengan sig sebesar 0,424 untuk uji 2 (dua) arah, sedangkan penelitian ini memiliki hipotesis satu arah, sehingga yang dipakai adalah uji 1 (satu) ekor / sig 1-tailed sebesar 0,212 ( $\mathrm{p}>0,05)$, yang berarti bahwa data pada variabel burnout memiliki sebaran atau berdistribusi normal. Uji normalitas pada variabel bullying diperoleh koefisien KS-Z = 0,987 dengan Sig sebesar 0,285 untuk uji 2 (dua) arah dan sig sebesar 0,1425 untuk uji 1 (satu) arah ( $\mathrm{p}>0,05)$, yang berarti bahwa data pada variabel bullying sebaran atau berdistribusi normal. Hasil uji normalitas dapat dilihat pada tabel 3. 
Tabel 4

Hasil Uji Linieritas

\begin{tabular}{lllll}
\hline Variabel & F & Sig & p & Keterangan \\
\hline $\begin{array}{l}\text { Burnout } \\
\text { Bullying }\end{array}$ & 17.005 & 0,000 & $\mathrm{p}<0,05$ & Linear \\
\hline
\end{tabular}

Berdasarkan tabel 4 di atas dapat dikatakan bahwa variabel burnout dan bullying memiliki hubungan linear. Hal ini terlihat dari nilai $p$ yang diperoleh yaitu 0,000 maka $p<0,05$ maka dapat disimpulkan adalah kedua variabel memiliki hubungan linear dan telah memenuhi syarat untuk dilakukan analisa korelasi Product Moment (Pearson Correlation).

Tabel 5

Korelasi Antara Burnout dengan Bullying

\begin{tabular}{lll}
\hline Analisis & Pearson Correlation & Signifikansi (p) \\
\hline Korelasi & 0,434 & 0,000 \\
\hline
\end{tabular}

Pada tabel 5, hasil uji korelasi membuktikan bahwa ada hubungan signifikan antara kejadian burnout dan bullying. Hal ini ditunjukkan dengan koefisien korelasi (Pearson) sebesar 0,434 dan nilai $\mathrm{p}=0,00(\mathrm{p}<0,05)$. Dari hasil perhitungan tersebut, maka hipotesis yang diajukan dalam penelitian ini menunjukkan ada hubungan positif antara burnout dan bullying dinyatakan dapat diterima.

Tabel 6

Sumbangan Efektif

\begin{tabular}{lllll}
\hline Model & $R$ & $R$ Square & Adjusted R Square & Std. Error of the Estimate \\
\hline 1 & $.434^{\mathrm{a}}$ & .188 & .694 & 0.482 \\
\hline
\end{tabular}

Berdasarkan tabel 6 di atas, dapat dilihat bahwa dalam penelitian ini diperoleh koefisien determinasi sebesar 0,188. Berdasarkan hasil tersebut, dapat disimpulkan bahwa 18,8 persen bullying mempengaruhi burnout dan selebihnya 81,2 persen dipengaruhi oleh faktor lain yang tidak diteliti, seperti faktor jenis kelamin, dukungan sosial, persepsi terhadap lingkungan kerja, kepribadian karyawan, kecerdasan emosional, maupun konsep diri karyawan itu sendiri.

Hasil penelitian ini sejalan dengan yang dikemukakan oleh Allen, dkk., (2014), dimana mereka melakukan penelitian terhadap 762 perawat di Australia dan hasil penelitian tersebut menunjukkan bahwa bullying dan burnout memiliki hubungan positif yang signifikan dengan nilai korelasi $\mathrm{r}=0,38$ dan nilai $\mathrm{p}<0,001$, artinya semakin tinggi perilaku bullying yang di terima karyawan, maka burnout yang dialami juga semakin tinggi, dan semakin rendah 
perilaku bullying yang di terima karyawan, maka burnout yang di alami juga semakin rendah. Dari penelitian tersebut pula diharapkan dengan tingginya kejadian burnout tersebut dapat dilahirkan suatu kebijakan baru dari organisasi kesehatan untuk mencegah terjadinya kejadian burnout pada petugas kesehatan. Selain itu, diharapkan secara individual juga mampu mengurangi resiko terjadinya burnout dengan melakukan psychologically detaching di tempat mereka bekerja.

Penelitian ini menunjukkan rata-rata karyawan di PT Bank Central Asia Tbk cabang Asia memiliki burnout yang rendah dapat terlihat dari data penelitian terdapat 1 subjek dengan persentase 1,4 persen yang berada pada kategori rendah, kemudian 72 subjek dikategorikan mengalami burnout yang sedang dengan persentase 98,6 persen dan tidak ada subjek yang mengalami burnout yang tinggi. Berdasarkan penjelasan di atas dapat disimpulkan rata-rata karyawan di PT Bank Central Asia Tbk cabang Asia mengalami burnout yang rendah.

Berdasarkan hasil penelitian terhadap karyawan di PT Bank Central Asia Tbk cabang Asia yang menunjukkan kejadian rata-rata burnout yang cenderung rendah dengan persentase 98,6 persen karyawan mengalami burnout sedang terlihat dari hasil observasi dan wawancara terhadap beberapa subjek yang menyatakan bahwa mereka tidak pernah merasa tertekan dalam menghadapi rintangan dan tuntutan dalam bekerja, dan mayoritas atasan akan memberikan tugas yang sesuai dengan deskripsi pekerjaan mereka.

Namun, ketika tuntutan pekerjaan telah cukup banyak, maka akan ada kemungkinan mereka untuk kurang peka terhadap individu maupun lingkungan sekitar mereka sehingga dapat memicu timbulnya burnout. Hal tersebut juga dibuktikan dari mayoritas karyawan di PT Bank Central Asia Tbk cabang Asia menyatakan bahwa walaupun tuntutan pekerjaan mereka cukup banyak, mereka akan selalu menerima tugas baru yang diberikan oleh atasan. Hasil observasi dan wawancara diatas didukung oleh data penelitian yang terlihat pada skor burnout yang menunjukkan bahwa dari 73 subjek penelitian, terdapat 1 subjek yang mendapatkan total skor $<60,72$ subjek mendapat total skor $60-90$, dan tidak ada satu pun subjek penelitian dengan skor burnout diatas 90 .

Pada karyawan dengan tingkat kejadian burnout yang tergolong rendah dijumpai pada 1 subjek penelitian. Dari hasil observasi dan wawancara yang telah dilakukan, karyawan tersebut merasa bahwa pekerjaannya cukup menyenangkan dan tidak membosankan sama sekali. Ia juga yakin dapat mengerjakan tugas-tugas dengan baik walaupun tugas itu sangat berat. Semua kelancaran pekerjaan karyawan tersebut ia lakukan karena ia yakin akan kemampuan diri yang ia miliki. Karyawan tersebut juga mengaku mampu mengandalkan teman-temannya yang lain saat 
bekerja dalam tim, bahkan ia tidak segan-segan untuk membantu rekan kerjanya yang lain ketika pekerjaannya telah selesai.

Penelitian ini juga meneliti tentang perilaku bullying yang terjadi di PT Bank Central Asia Tbk cabang Asia. Hasil penelitian menunjukkan bahwa tidak ditemukan adanya perilaku bullying yang tergolong tinggi, namun dijumpai sebanyak 57 subjek dengan perilaku bullying yang tergolong sedang, dan terdapat 16 subjek dengan perilaku bullying yang tergolong rendah.

Pada karyawan dengan kategori perilaku bullying rendah ditemukan sebanyak 16 subjek penelitian. Berdasarkan hasil observasi dan wawancara terhadap para karyawan didapatkan bahwa mereka selalu mendapatkan instruksi yang jelas oleh atasan sehingga hal tersebut memudahkan mereka dalam bekerja, dan dalam penyampaiannya pun disampaikan secara sopan dan jelas. Atasan pun selalu memberi sambutan yang ramah setiap berpapasan. Rekan kerja juga bersedia dalam membantu menyelesaikan pekerjaan yang kurang mereka pahami. Atasan pun tidak melakukan pemantauan secara berlebihan pada saat bekerja, sehingga mereka tidak merasakan adanya tindakan bullying yang berarti di tempat mereka bekerja sekarang ini. Selanjutnya, terdapat pula karyawan dengan kategori perilaku bullying sedang yang ditemukan sebanyak 57 subjek penelitian. Dari hasil wawancara dan observasi yang telah dilakukan, para karyawan sering mendengar adanya gosip yang belum tentu benar mengenai diri mereka di lingkungan kerja. Ada kadang kalanya mereka juga tidak berani bercerita banyak kepada rekan kerja baik masalah pekerjaan maupun kehidupan pribadi mereka oleh karena takut menjadi bahan gosip di lingkungan kerja, sehingga mereka lebih memilih untuk menyimpan cerita tersebut sendiri. Disamping itu, ada kadang kalanya waktu untuk istirahat jam makan siang terpotong terutama ketika sedang banyak menghadapi nasabah perbankan. Meskipun demikian, mereka merasa cukup diapresiasi oleh atasan atas pencapaian kerja yang mereka lakukan, mereka tidak pernah mengalami perlakukan intimidasi seperti didorong maupun ditunjuk-tunjuk oleh rekan kerja ataupun atasan, sehingga kejadian bullying pada kelompok ini secara umum masih tergolong dalam kategori sedang.

Dalam penelitian ini juga ditemukan bahwa nilai rata - rata empirik bullying lebih kecil dari nilai hipotetiknya $(65,26<75)$ dengan selisih nilai sebanyak 9,74 dan nilai rata - rata empirik bullying yang didapatkan ini termasuk dalam kategorisasi nilai bullying di tempat kerja yang rendah. Hal ini menujukkan bahwa tingkat bullying yang dimiliki oleh subjek penelitian tergolong rendah. Sedangkan untuk burnout, nilai rata - rata empirik burnout lebih kecil dari nilai hipotetiknya $(72,00<75)$ dengan selisih nilai sebanyak 3,00 dan nilai rata - rata empirik 
burnout yang didapatkan ini termasuk ke dalam kategorisasi nilai burnout yang rendah. Hal ini menunjukkan bahwa tingkat burnout yang dimiliki oleh subjek penelitian tergolong rendah. Hasil penelitian ini juga menunjukkan bahwa koefisien korelasi Pearson yang didapat sebesar 0,434 dengan $\mathrm{p}<0,05$. Berdasarkan hal tersebut, dapat disimpulkan bahwa semakin tinggi perilaku bullying yang terjadi dalam suatu perusahaan, maka semakin tinggi pula kejadian burnout yang akan dialami oleh karyawannya, atau semakin rendah perilaku bullying yang terjadi dalam suatu perusahaan, maka semakin rendah pula kejadian burnout yang akan dialami oleh karyawannya.

Ada beberapa kemungkinan yang membuat ada hubungan positif dan signifikan antara kedua variabel tersebut. Pertama, yaitu secara umum karyawan menganggap bahwa mereka dalam bekerja cenderung mengalami perlakuan tidak menyenangkan dari teman - temannya sehingga mereka merasa tertekan dan akibatnya mengalami burnout. Pernyataan tersebut didukung oleh hasil temuan dari Trepanier, dkk., (2013) bahwa adanya persaingan kerja yang kurang sehat antara sesama rekan kerja merupakan kondisi lingkungan kerja yang dapat mempengaruhi berbagai masalah. Kelloway \& Day (2005) juga menyatakan bahwa lingkungan kerja yang baik adalah lingkungan kerja yang sehat, dimana setiap instansi atau organisasi harus mampu mendukung kesehatan karyawan secara fisik maupun psikologis, serta membantu karyawan menguasai pekerjaan, serta menghadapi hal - hal seperti stress dan tekanan. Tidak terwujudnya lingkungan kerja yang baik juga pastinya akan berdampak pada kehidupan kerja setiap karyawan.

Kedua, besarnya aktivitas fisik maupun psikologis yang dilakukan oleh karyawan secara tidak langsung akan berdampak pada interaksi di lingkungan kerja mereka sehingga akan meningkatkan perilaku bullying. Hal tersebut sejalan dengan hasil penelitian yang dilakukan oleh Romadhoni, dkk., (2015) dimana pada penelitian tersebut terlihat bahwa beban kerja yang akan dipertanggung jawabkan dan banyaknya jumlah individu yang harus dilayani menyebabkan karyawan tersebut merasa mempunya beban kerja besar yang harus dipikul hingga melampaui batas kemampuan mereka sehingga sangat potensial untuk menyebabkan kejenuhan kerja. Lingkungan kerja yang buruk juga menyebabkan timbulnya kelelahan kerja, ketegangan emosi serta menurunkan motivasi dari karyawan yang bekerja di sana dan menyebabkan kurang harmonisnya hubungan antar karyawan yang terlihat dalam bentuk tidak terjalinnya komunikasi yang efektif antar karyawan. 


\section{SIMPULAN}

Berdasarkan penjelasan di atas dapat disimpulkan bahwa tinggi-rendahnya bullying yang di alami karyawan PT Bank Central Asia Tbk cabang Asia, dapat berpengaruh terhadap kejadian burnout di tempat kerja tersebut. Merujuk dari pemaparan tersebut, maka dapat dikatakan bahwa ada hubungan positif dan signifikan antara bullying dengan burnout yang di alami karyawan di PT Bank Central Asia Tbk cabang Asia. Artinya, semakin rendah bullying yang di alami oleh karyawan maka semakin rendah burnout karyawan pada perusahaan. Atau sebaliknya semakin tinggi bullying yang di alami karyawan maka semakin tinggi burnout karyawan pada perusahaannya.

Berdasarkan kesimpulan yang telah diuraikan, peneliti mengemukakan beberapa saran yang diharapkan dapat berguna untuk kelanjutan studi korelasional ini. Bagi perusahaan, pihak manajemen diharapkan dapat memberi kesempatan kepada setiap karyawan untuk melakukan intersopeksi dari setiap perilakunya yang dapat membuat orang lain (teman kerjanya) mengalami pembulian sehingga tertekan yang dapat mengakibatkan terjadinya burnout. Hal tersebut dapat dilakukan dengan cara menyediakan wadah dan dipandu oleh manajer HRD agar setiap karyawan dapat mengekspresikan perasaan mereka dengan cara sharing atau diskusi halhal yang konstruktif dan mendukung diantara mereka agar bekerja secara lebih produktif.

Bagi karyawan, diharapkan untuk menggunakan waktu kerja atau waktu luangnya dengan cara saling memberi dukungan satu sama lain untuk mengurangi perilaku bullying dan terjadinya burnout di antara mereka. Hal tersebut dilakukan dengan cara saling menghargai dan menghormati orang lain dalam wadah yang sudah disediakan oleh pihak manajemen. Bagi peneliti selanjutnya, diharapkan dapat meneliti faktor-faktor lain yang mempengaruhi kejadian burnout seperti dukungan sosial, persepsi terhadap lingkungan kerja, kepribadian karyawan, kecerdasan emosional, konsep diri, maupun jenis kelamin dan usia.

\section{DAFTAR PUSTAKA}

Allen, B.C., Holland, P., \& Reynolds, R. (2014). The Effect of Bullying on Burnout in Nurses: The Moderating Role of Psychological Detachment. Journal of Advanced Nursing, 71(2), 381-390.

Andriansyah, H., \& Sahrah, A. (2014). Hubungan Bullying dengan Burnout pada Karyawan. Jurnal Psikologi Tabularasa, 9(2), 137-150.

Arikunto, S. (2006). Prosedur Penelitian: Suatu pendekatan Praktik. Jakarta : Rineka Cipta. 
Ballou, B., \& Godwin. H. N. (2007). Quality of Work Life: Have You Invested in Your Organizational Future?.Strategic Finance, 89(4), 41- 45.

Einarsen, S., \& Raknes, B. (1997). Harrassment in Workplace and Victimization of Men. Violence and Victims, 12(3), 247-263.

Einarsen, S., Hoel, H., \& Notelaers, G. (2009). Measuring Exposure to Bullying and Harassment at Work: Validity, Factor Structure, and Psychometric Properties of the Negative Acts Questionnaire-revised. Work \& Stress, 23(1), 24-44.

Harter, J. K., Schmidt, F. L., \& Keyes, C. M. (2002). Well-Being in the Workplace and its Relationship to Business Outcomes. A Review of the Gallup Studies.

Kelloway, E. K., \& Day, L. A. 2005. Building Healthy Workplaces: What We Know so Far. Canadian Journal of Behavioural Science, 37(4), 223-249.

Kreitner, R., Kinicki, A. (1992). Organizational Behavior.second edition. Boston: Richard, D. Irwin, Inc.

Lorenz, K. (2006). Five Signs of Job Burnout and What to do About It.

Maharani, P.A. \& Triyoga, A. (2012). Kejenuhan Kerja (Burnout) dengan Kinerja Perawat dalam Pemberian Asuhan Keperawatan. Jurnal STIKES, 5(2), 167-178.

Maslach, C., \& Leiter, M.P. (1997). The Truth about Burnout: How Organizations Cause Personal Stress and What to do About It. San Fransisco: Bass Publishers

Miller, D.(2000). Dying to Care? : Work, Stress and Burnout in HIV/AIDS. New York: Simultaneously Published

Rayner, C., Hoel, H., \& Cooper, C. L. (2002). Workplace Bullying: What We Know, Who is to Blame, and What Can We Do?. New York: Taylor and Francis.

Romadhoni, L.C., Asnomy, T., \& Suryatni, M. 2015. Pengaruh beban kerja, lingkungan kerja, dan dukungan sosial terhadap burnout pustakawan di Kota Mataram. Jurnal Ilmu Perpustakaan, Informasi, dan Kearsipan Khizanah Al-Hikmah, 3(2), 125 - 145.

Rudi, T. (2010). Informasi Perihal Bullying. Jakarta : Indonesian Anti Bullying.

Trepanier, S., Fernet, C., \& Austin, S. 2013. Workplace Bullying and Psychological Health at Work: The Mediating Role of Satisfaction of Needs for Autonomy, Competence and Relatedness. Work and Stress, 27(2), 123-140. 